\title{
Activation of Host Pattern Recognition Receptors by Viruses
}

Kiva Brennan \& Andrew G. Bowie

School of Biochemistry \& Immunology, Trinity College Dublin, Dublin 2, Ireland.

Corresponding Author: Andrew G. Bowie, School of Biochemistry \& Immunology, Trinity College Dublin, Dublin 2, Ireland. agbowie@tcd.ie

\section{Short Title: Innate immune detection of viruses}

\section{Summary}

Viral recognition by the host innate immune system has become an exciting and growing area of research focus in recent years. It is now apparent that multiple pattern recognition receptor (PRR) families, including Toll-like receptors (TLRs), RIG-I-like receptors (RLRs) and NOD-like receptors (NLRs), contribute significantly to viral detection by sensing viral proteins and nucleic acids, leading to induction of cytokines and type I interferons (IFNs). Of particular current interest is the sensing of viral DNA within infected cells, since the PRRs responsible for this are only partially defined. Recently RNA polymerase III (Pol III) was shown to transcribe some viral DNAs into RNA for detection by RIG-I, leading to IFN induction. Another novel mechanism of viral DNA recognition unveiled, leading to proinflammatory cytokine production, involves the PYHIN family member AIM2.

\section{Introduction}

Viral infection of host cells gives rise to IFN $\beta$ and interleukin-1 $\beta$ (IL-1 $\beta)$ production, both of which are essential for host immunity to viruses[1]. IFN $\beta$ induction requires activation of the transcription factors IFN regulatory factor $3(\mathrm{IRF} 3)$ and NFKB, while IL-1 $\beta$ production 
involves inflammasome formation[1]. The PRRs involved in eliciting these responses to viral infection had been poorly characterised, however, within the last 2-3 years the knowledge surrounding recognition of viral PAMPS by PRRs in host cells has increased dramatically (see Figure 1). Recent studies have clarified the roles played by TLRs, RLRs and NLRs in recognising specific viruses[2], and have also identified entirely novel receptors for viral nucleic acids. Further, current understanding of host-virus interactions suggests that there are more PRRs for viral nucleic acid yet to be discovered. Here we review these recent developments and highlight some particularly surprising discoveries.

\section{Cell Surface TLRs and Viruses}

TLRs are well known to be involved in the detection of multiple pathogens. TLR2 and TLR4 are two cell surface TLRs best known for their role in sensing extracellular pathogens. For example, TLR2 recognises bacterial lipopeptides and various fungal PAMPs [3,4], while TLR4 senses Gram-negative lipopolysaccharide. However recent studies have highlighted the importance of TLR2 \& TLR4 in the anti-viral response. Barbalat et al. [5] used cells deficient in TLR2 and TLR9 to show that TLR2 plays a major role in viral recognition in cells derived from the spleen and bone marrow, and that TLR2 activation by an unidentified virusderived ligand led to production of type I IFN, a classic anti-viral response. The cells responsible for this anti-viral response were identified as inflammatory monocytes, and were shown to be capable of discriminating between bacterial and viral ligands and activating separate sets of genes depending on the stimulus [5].

A novel role for TLR4 in vaccinia virus (VACV) immunity has also been uncovered. Following VACV infection, mice lacking functional TLR4 had greater viral replication, hypothermia and mortality than wild type mice [6]. A novel VACV ligand, rather than an endogenous ligand for TLR4 was invoked here, and it will be of interest both in the case of this and the TLR2 study to see what viral PAMPs are identified for these PRRs in the future. 


\section{Endosomal TLRs and viruses}

The endosomal TLRs (TLR3, TLR7, TLR8 and TLR9) have traditionally been more strongly linked to anti-viral immunity than the cell surface TLRs, recognising as they do viral nucleic acids, and their roles in sensing viruses are further emphasised by recent studies.

Several studies have highlighted a sensing role for TLR3 in virus infection as a receptor for viral dsRNA (reviewed in [7]). Oddly, and in contrast to TLR4, TLR3 has actually been shown to play a positive role for VACV during infection, since TLR3-deficient mice showed reduced disease morbidity and improved survival relative to wild-type mice following VACV infection [8]. However TLR3 has become one of the few TLRs to be implicated with a protective role in human viral infections: children with herpes simplex virus-1 (HSV-1) encephalitis were found to have a dominant-negative TLR3 allele [9]. Although TLR3 was seen to be redundant in host defense to HSV-1 in epithelial and dendritic cells, expression of TLR3 in the CNS was essential for immunity to HSV-1 [9].

Another recent human study involving TLR3 and relating to Epstein-Barr virus (EBV) has shown that TLR3 can recognise single-stranded non-coding RNA from EBV [10]. The EBVencoded small RNA (EBER) found in EBV-infected cells can form a stem loop structure which gives rise to dsRNA-like molecules. RNA purified from the sera of patients with chronic active EBV infection (CAEBV) and EBV-associated hemophagocytic lymphohistiocytosis (EBV-HLH) was capable of inducing TLR3 signalling in EBV-transformed lymphocytes and peripheral mononuclear cells. This study highlighted the importance of TLR3 in recognition of EBER, but also the involvement of TLR3 in immunopathologic diseases caused by active EBV infection [10].

TLR7 is known to respond to ssRNA, and another example of a link between TLRs and human disease comes from data showing that responses to HIV-1-encoded TLR7 ligands differ markedly between male and female plasmacytoid dendritic cells[11]. This is now 
thought to be one reason for known differences in HIV-1 disease progression between men and women [11]. A further human pathogen that has been added to the list of viruses sensed by TLR7 is West Nile virus (WNV). Two studies using murine models of WNV infection showed increased susceptibility to lethal WNV encephalitis, and an impaired host immune response to the virus [12] [13].

\section{Viral RNA, RLRs and MAVS}

The RLRs retinoic acid-inducible gene I (RIG-I) and melanoma differentiation-associated gene 5 (MDA5) are RNA helicases that have previously been identified as critical receptors for the activation of antiviral immunity by viral RNA [14], and recently the exact nature of the RNA ligands recognised by RLRs have been uncovered.

In 2006, two groups uncovered important information regarding the ligand for RIG-I. Pichlmair et al [15] demonstrated that influenza A virus infection, which does not generate dsRNA, can still activate RIG-I. RIG-I was shown to be activated by viral genomic singlestranded RNA (sSRNA) bearing a 5'-triphosphate [15]. Hornung et al [16] simultaneously showed that 5'-triphosphate RNA bound directly to RIG-I. These studies highlighted that uncapped 5'-triphosphate RNA, which is present in viruses detected by RIG-I, but absent in viruses recognised by MDA- 5 such as the picornaviruses, is a molecular signature for the detection of viral infection by RIG-I [16]. The exact viral RNA motifs capable of initiating an antiviral response through RIG-I were further characterised by Schmidt et al [17] and Schlee et al [18]. These studies found that a 5'-triphosphate group on RNA was not sufficient to cause antiviral signalling through RIG-I but that RNA structures also need a blunt ended region of dsRNA adjacent to the 5'-triphosphate to initiate signalling $[17,18]$. Importantly, this explains how RIG-I recognises negative-stranded RNA viruses such as rabies, since such viruses have these blunt end 5'-triphosphate motifs at the end of their ssRNA genomes. 
Further, a recent study showed definitively that RIG-I directly recognises viral genomes: using Influenza A and Sendai virus the authors showed that RIG-I agonists are exclusively generated during viral replication and correspond to full-length viral genomes [19].

In the case of MDA5, the ligand had been assumed to be long linear dsRNA, and indeed Pichlmair et al showed that dsRNA extracted from encephalomyocarditis virus- or VACVinfected cells could induce MDA5-dependent Type I IFN [20]. However the stimulatory activity of the RNA resided in higher order structures containing both ss and dsRNA, leading to the conclusion that MDA5 recognises a mesh of web-like RNA web generated during the viral life cycle rather than long dsRNA [20].

Both RIG-I and MDA-5 signal through the adaptor MAVS via caspase recruitment domain (CARD) homotypic interactions [21-24]. As such, MAVS is a critical anti-viral signalling adaptor protein, and in fact has been recently shown for the first time to also mediate a nonRLR anti-viral response: NOD2, a receptor that was previously believed to be restricted to the sensing of bacterial ligands, was shown to bind and respond to single-stranded RNA and activate IRF3, leading to IFN $\beta$ production [25]. NOD2, which has a CARD, was shown signal via MAVS, and was required in vivo for host defense against RSV [25]. Thus NOD2 has a novel function as an anti-viral PRR.

\section{Viral Sensing, inflammasome activation and IL-1}

Many viruses are known to stimulate IL-1 $\beta$ production, which is important for the host inflammatory response to viruses and also to the induction of fever. After transcriptional upregulation of the IL1B gene, IL-1 $\beta$ production is mediated by caspase 1 which cleaves the precursor inactive protein pro-IL-1 $\beta$ into the active form. Caspase 1 functions in large complexes termed inflammasomes, the best characterised of which contain NALP3. For 
example, NALP3 has recently been shown to be necessary for IL-1 $\beta$ production in response to adenovirus infection [26] and to RNA derived from influenza [27].

NALP3-independent viral stimulation of IL-1 $\beta$ production has also recently been shown to occur, leading to the discovery of yet another novel viral PRR, absent in melanoma 2 (AIM2). AIM2 was identified as an IFN-inducible protein that can activate the inflammasome in response to VACV [28] and cytosolic DNA [28-31]. This is consistent with the domain structure of AIM2, which contains a HIN domain capable of binding DNA, and like NALP3, a pyrin domain that is required for inflammasome activation. Expression of AIM2 caused inflammasome formation, and knockdown of endogenous AIM2 siRNA verified its importance for dsDNA-induced inflammsome activation and IL-1 $\beta$ production in human and murine cells [28-30] [31].

\section{Cytosolic Sensing of Viral DNA for IFN $\beta$ induction}

It is now well known that cytoplasmic DNA sensing pathways exist to detect exogenous DNA, which involve activation of the transcription factor IRF3, via TBK1, leading to induction of IFN $\beta$ [32], and that such response pathways are critical both for anti-viral immunity, and as triggers of autoimmunity [33]. Although novel downstream signalling components involved in DNA sensing pathways, such as DDX3 [34-36] and STING [37], continue to be identified, and although high mobility group proteins have recently been implicated in delivering nucleic acid to PRRs for detection [38], identification of cytoplasmic DNA PRRs (that could bind DNA and transmit a signal to TBK1) remains elusive.

In 2007, DAI (DNA-dependent activator of IRFs) was implicated as such a PRR [39]. That study showed that overexpression of DAI (DLM-1/ZBP1) in murine fibroblasts enhanced induction of type I IFN and other innate immune genes associated with DNA responses. Silencing of the protein inhibited DNA-induced signalling, and the binding of DAI to dsDNA 
induced association of the protein with IRF3 and TBK1 [39]. Further work showed that the DNA binding domains of DAI, and dimerisation were critical for full activation of the pathway [40]. DAI has now been show to be important for the antiviral immune response to Human cytomegalovirus (HCMV). It was observed that DAI was essential for IRF3 activation and IFN $\beta$ expression triggered by HCMV, and that overexpression of DAI could inhibit replication of HCMV [36]. From this work, the authors suggested that DAI is the principal PRR for the IFN $\beta$ response to HCMV infection. However, further work showed that DAI is only responsible for IFN $\beta$ responses in restricted cells since knockdown of DAl in several cell types had little effect on the IFN $\beta$ response to exogenous DNA [41]. Importantly, another study showed that adjuvant effect of DNA vaccines in vivo, which occurs through PRR sensing of exogenous DNA, was dependent on TBK1, but independent of DAI [42].

Two groups identified an additional cytoplasmic DNA sensing pathway in 2009, which surprisingly for a DNA response, involved RIG-I and MAVS $[43,44]$. One type of DNA known to induce IFN $\beta$ when transfected in the cytoplasm is the B-form synthetic dsDNA poly(dA$d T)^{*}$ poly $(d A-d T)($ poly $(d A-d T))$. This is used as a surrogate synthetic mimic for AT-rich pathogen DNA, in much the same way that Poly $(\mathrm{I}: \mathrm{C})$ is used to mimic viral RNA responses. It was shown that Pol III transcribed poly(dA-dT) into an RNA-containing a 5'-triphosphate moiety, which could then be sensed by RIG-I leading to IFN $\beta$ induction $[43,44]$. This pathway was also shown to be important in the sensing of EBV EBERs, which were transcribed by RNA polymerase III and then triggered RIG-I activation [43]. Thus EBERs are sensed by both TLR3 (see above) and RIG-I.

Many different types of pathogen DNA, and not just that which is AT-rich, have been shown to induce IFN $\beta$ through cytoplasmic PRR sensing [33]. Given that the role of DAI is very cell type specific, and that the Pol III-RIG-I pathway only senses AT-rich DNA, additional cytoplasmic DNA PRRs remain to be discovered. 


\section{Conclusions and future perspectives}

This review has illustrated the often dramatic and surprising discoveries made over the past few years, in terms of how host PRRs sense viruses. As well as heightened understanding of how known viral PRRs function, completely new PRRs have been discovered, and knowledge of the relevance of PRRs for distinct viruses, and in human disease, has increased.

In the near future, we can look forward to gaining further insights into the role of viral PRRs not only in human viral disease, but also in autoimmunity. Importantly, the role of novel PRRs such as AIM2 remains to be determined in vivo, through the use of knock-out mice. It will also be important to determine which viruses are sensed by the Pol-III-RIG-I pathway in vivo. The identification of cytoplasmic PRRs for non-AT rich pathogen DNA also remains a challenge [33], while another challenge will be to explain the ability of host cytoplasmic PRRs to discriminate between self and non-self DNA, which is now well-defined in the case of RNA.

\section{Acknowledgements}

This work is supported by Science Foundation Ireland grant 07/IN1/B934.

\section{Conflict of Interest}

The authors declare no conflict of interest.

\section{References}

Papers of particular interest, published within the period of review, have been highlighted as:

- of special interest

-• of outstanding interest 
1. Ishii KJ, Koyama S, Nakagawa A, Coban C, Akira S: Host innate immune receptors and beyond: making sense of microbial infections. Cell Host Microbe 2008, 3:352-363.

2. Kawai T, Akira S: The roles of TLRs, RLRs and NLRs in pathogen recognition. Int Immunol 2009, 21:317-337.

3. Goodridge HS, Underhill DM: Fungal Recognition by TLR2 and Dectin-1. Handb Exp Pharmacol 2008:87-109.

4. Zahringer $U$, Lindner B, Inamura S, Heine H, Alexander C: TLR2 - promiscuous or specific? A critical re-evaluation of a receptor expressing apparent broad specificity. Immunobiology 2008, 213:205-224.

5. Barbalat R, Lau L, Locksley RM, Barton GM: Toll-like receptor 2 on inflammatory monocytes induces type I interferon in response to viral but not bacterial ligands. Nat Immunol 2009, 10:1200-1207.

6. Hutchens MA, Luker KE, Sonstein J, Nunez G, Curtis JL, Luker GD: Protective effect of Toll-like receptor 4 in pulmonary vaccinia infection. PLoS Pathog 2008, 4:e1000153.

7. Vercammen E, Staal J, Beyaert R: Sensing of viral infection and activation of innate immunity by toll-like receptor 3. Clin Microbiol Rev 2008, 21:13-25.

8. Hutchens M, Luker KE, Sottile P, Sonstein J, Lukacs NW, Nunez G, Curtis JL, Luker GD: TLR3 increases disease morbidity and mortality from vaccinia infection. J Immuno/ 2008, 180:483-491.

9. Zhang SY, Jouanguy E, Ugolini S, Smahi A, Elain G, Romero P, Segal D, Sancho-Shimizu V, Lorenzo L, Puel A, et al.: TLR3 deficiency in patients with herpes simplex encephalitis. Science 2007, 317:1522-1527. 
10. Iwakiri D, Zhou L, Samanta M, Matsumoto M, Ebihara T, Seya T, Imai S, Fujieda M, Kawa K, Takada K: Epstein-Barr virus (EBV)-encoded small RNA is released from EBV-infected cells and activates signaling from Toll-like receptor 3. J Exp Med 2009, 206:2091-2099.

11. Meier A, Chang JJ, Chan ES, Pollard RB, Sidhu HK, Kulkarni S, Wen TF, Lindsay RJ, Orellana L, Mildvan D, et al.: Sex differences in the Toll-like receptor-mediated response of plasmacytoid dendritic cells to HIV-1. Nat Med 2009, 15:955-959.

12. Town T, Bai F, Wang T, Kaplan AT, Qian F, Montgomery RR, Anderson JF, Flavell RA, Fikrig E: Tolllike receptor 7 mitigates lethal West Nile encephalitis via interleukin 23-dependent immune cell infiltration and homing. Immunity 2009, 30:242-253.

13. Welte T, Reagan K, Fang H, Machain-Williams C, Zheng X, Mendell N, Chang GJ, Wu P, Blair CD, Wang T: Toll-like receptor 7-induced immune response to cutaneous West Nile virus infection. J Gen Virol 2009, 90:2660-2668.

14. Yoneyama M, Fujita T: RNA recognition and signal transduction by RIG-I-like receptors. Immunol Rev 2009, 227:54-65.

15. Pichlmair A, Schulz O, Tan CP, Naslund TI, Liljestrom P, Weber F, Reis e Sousa C: RIG-I-mediated antiviral responses to single-stranded RNA bearing 5'-phosphates. Science 2006, 314:9971001.

16. Hornung V, Ellegast J, Kim S, Brzozka K, Jung A, Kato H, Poeck H, Akira S, Conzelmann KK, Schlee M, et al.: 5'-Triphosphate RNA is the ligand for RIG-I. Science 2006, 314:994-997.

17. Schmidt A, Schwerd T, Hamm W, Hellmuth JC, Cui S, Wenzel M, Hoffmann FS, Michallet MC, Besch R, Hopfner KP, et al.: 5'-triphosphate RNA requires base-paired structures to activate antiviral signaling via RIG-I. Proc Natl Acad Sci U S A 2009, 106:12067-12072.

18. Schlee M, Roth A, Hornung V, Hagmann CA, Wimmenauer V, Barchet W, Coch C, Janke M, Mihailovic A, Wardle G, et al.: Recognition of 5' triphosphate by RIG-I helicase requires short blunt double-stranded RNA as contained in panhandle of negative-strand virus. Immunity 2009, 31:25-34. 
19. Rehwinkel J, Tan CP, Goubau D, Schulz O, Pichlmair A, Bier K, Robb N, Vreede F, Barclay W, Fodor E, et al.: RIG-I detects viral genomic RNA during negative-strand RNA virus infection. Cell 140:397-408.

20. Pichlmair A, Schulz O, Tan CP, Rehwinkel J, Kato H, Takeuchi O, Akira S, Way M, Schiavo G, Reis e Sousa C: Activation of MDA5 requires higher-order RNA structures generated during virus infection. J Virol 2009, 83:10761-10769.

21. Seth RB, Sun L, Ea CK, Chen ZJ: Identification and characterization of MAVS, a mitochondrial antiviral signaling protein that activates NF-kappaB and IRF 3. Cell 2005, 122:669-682.

22. Kawai T, Takahashi K, Sato S, Coban C, Kumar H, Kato H, Ishii KJ, Takeuchi O, Akira S: IPS-1, an adaptor triggering RIG-I- and Mda5-mediated type I interferon induction. Nat Immunol 2005, 6:981-988.

23. Meylan E, Curran J, Hofmann K, Moradpour D, Binder M, Bartenschlager R, Tschopp J: Cardif is an adaptor protein in the RIG-I antiviral pathway and is targeted by hepatitis C virus. Nature 2005, 437:1167-1172.

24. Xu LG, Wang YY, Han KJ, Li LY, Zhai Z, Shu HB: VISA is an adapter protein required for virustriggered IFN-beta signaling. Mol Cell 2005, 19:727-740.

25. Sabbah A, Chang TH, Harnack R, Frohlich V, Tominaga K, Dube PH, Xiang Y, Bose S: Activation of innate immune antiviral responses by Nod2. Nat Immunol 2009, 10:1073-1080.

26. Muruve DA, Petrilli V, Zaiss AK, White LR, Clark SA, Ross PJ, Parks RJ, Tschopp J: The inflammasome recognizes cytosolic microbial and host DNA and triggers an innate immune response. Nature 2008, 452:103-107.

27. Ichinohe $T$, Lee HK, Ogura $Y$, Flavell $R$, Iwasaki A: Inflammasome recognition of influenza virus is essential for adaptive immune responses. J Exp Med 2009, 206:79-87.

28. Hornung V, Ablasser A, Charrel-Dennis M, Bauernfeind F, Horvath G, Caffrey DR, Latz E, Fitzgerald KA: AIM2 recognizes cytosolic dsDNA and forms a caspase-1-activating inflammasome with ASC. Nature 2009, 458:514-518. 
29. Burckstummer T, Baumann C, Bluml S, Dixit E, Durnberger G, Jahn H, Planyavsky M, Bilban M, Colinge J, Bennett KL, et al.: An orthogonal proteomic-genomic screen identifies AIM2 as a cytoplasmic DNA sensor for the inflammasome. Nat Immunol 2009, 10:266-272.

30. Fernandes-Alnemri T, Yu JW, Datta P, Wu J, Alnemri ES: AIM2 activates the inflammasome and cell death in response to cytoplasmic DNA. Nature 2009, 458:509-513.

31. Roberts TL, Idris A, Dunn JA, Kelly GM, Burnton CM, Hodgson S, Hardy LL, Garceau V, Sweet MJ, Ross IL, et al.: HIN-200 proteins regulate caspase activation in response to foreign cytoplasmic DNA. Science 2009, 323:1057-1060.

32. Stetson DB, Medzhitov R: Recognition of cytosolic DNA activates an IRF3-dependent innate immune response. Immunity 2006, 24:93-103.

33. Hornung V, Latz E: Intracellular DNA recognition. Nature Reviews Immunology 2010, 10:123-130.

34. Schroder M, Baran M, Bowie AG: Viral targeting of DEAD box protein 3 reveals its role in TBK1/IKKepsilon-mediated IRF activation. EMBO J 2008, 27:2147-2157.

35. Soulat D, Burckstummer T, Westermayer S, Goncalves A, Bauch A, Stefanovic A, Hantschel O, Bennett KL, Decker T, Superti-Furga G: The DEAD-box helicase DDX3X is a critical component of the TANK-binding kinase 1-dependent innate immune response. $E M B O \mathrm{~J}$ $2008,27: 2135-2146$.

36. DeFilippis VR, Alvarado D, Sali T, Rothenburg S, Fruh K: Human cytomegalovirus induces the interferon response via the DNA sensor ZBP1. J Virol 84:585-598.

37. Ishikawa H, Ma Z, Barber GN: STING regulates intracellular DNA-mediated, type I interferondependent innate immunity. Nature 2009, 461:788-792.

38. Yanai H, Ban T, Wang Z, Choi MK, Kawamura T, Negishi H, Nakasato M, Lu Y, Hangai S, Koshiba R, et al.: HMGB proteins function as universal sentinels for nucleic-acid-mediated innate immune responses. Nature 2009, 462:99-103. 
39. Takaoka A, Wang Z, Choi MK, Yanai H, Negishi H, Ban T, Lu Y, Miyagishi M, Kodama T, Honda K, et al.: DAI (DLM-1/ZBP1) is a cytosolic DNA sensor and an activator of innate immune response. Nature 2007, 448:501-505.

40. Wang Z, Choi MK, Ban T, Yanai H, Negishi H, Lu Y, Tamura T, Takaoka A, Nishikura K, Taniguchi T: Regulation of innate immune responses by DAI (DLM-1/ZBP1) and other DNA-sensing molecules. Proc Natl Acad Sci U S A 2008, 105:5477-5482.

41. Lippmann J, Rothenburg S, Deigendesch N, Eitel J, Meixenberger K, van Laak V, Slevogt H, N'Guessan P D, Hippenstiel S, Chakraborty T, et al.: IFNbeta responses induced by intracellular bacteria or cytosolic DNA in different human cells do not require ZBP1 (DLM1/DAI). Cell Microbiol 2008, 10:2579-2588.

42. Ishii KJ, Kawagoe T, Koyama S, Matsui K, Kumar H, Kawai T, Uematsu S, Takeuchi O, Takeshita F, Coban C, et al.: TANK-binding kinase-1 delineates innate and adaptive immune responses to DNA vaccines. Nature $2008,451: 725-729$.

43. Ablasser A, Bauernfeind F, Hartmann G, Latz E, Fitzgerald KA, Hornung V: RIG-I-dependent sensing of poly(dA:dT) through the induction of an RNA polymerase III-transcribed RNA intermediate. Nat Immunol 2009, 10:1065-1072.

44. Chiu YH, Macmillan JB, Chen ZJ: RNA polymerase III detects cytosolic DNA and induces type I interferons through the RIG-I pathway. Cell 2009, 138:576-591. 


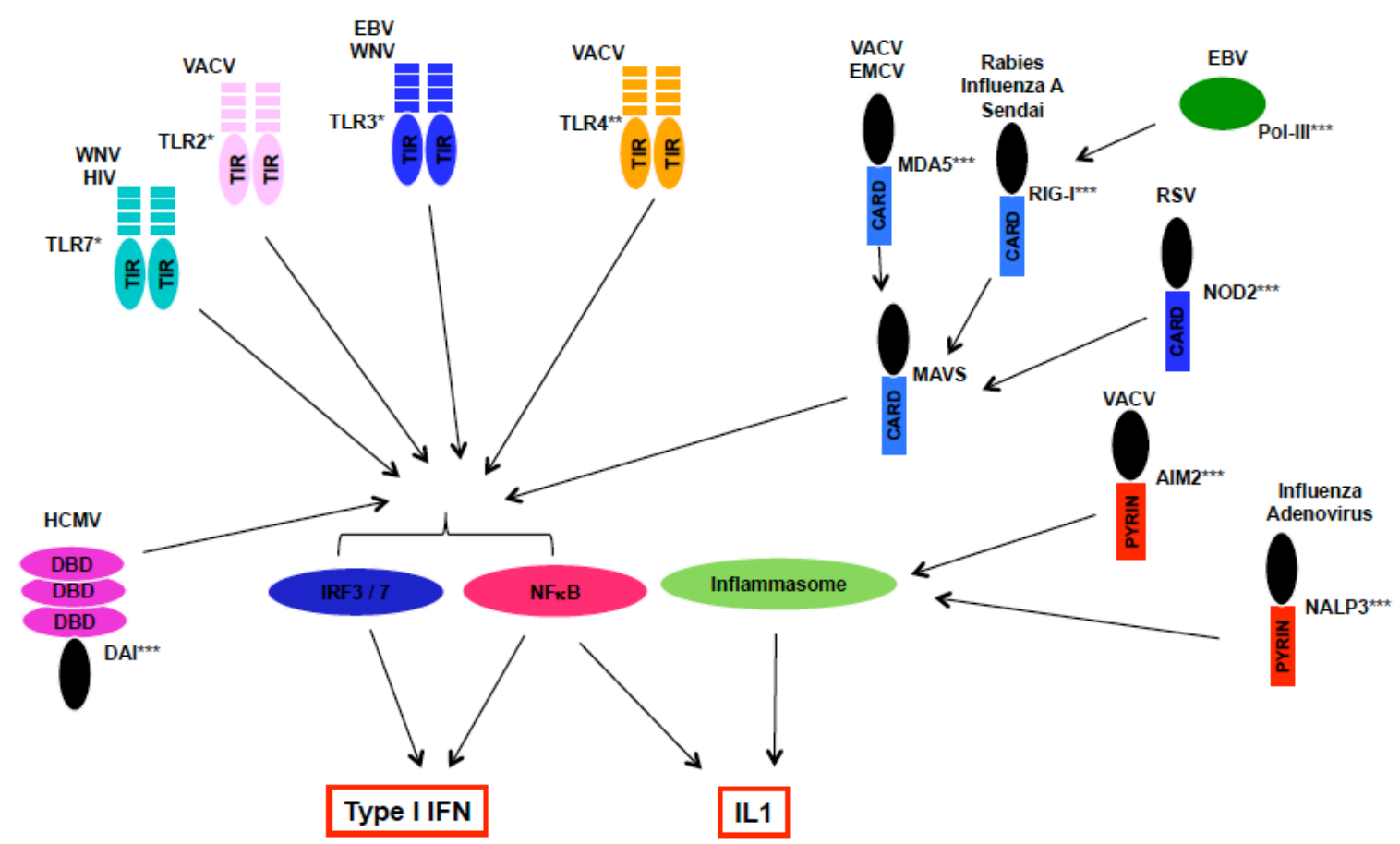

Figure 1. Recognition of viruses by host pattern recognition receptors. Recent advances in understanding the role of TLRs, RLRs and novel viral PRRs in sensing viruses are shown. Arrows indicate signal transduction pathways leading to activation of the transcription factors IRF3 and NFKB, and to the inflammasome, giving rise to type I IFN and IL-1 $\beta$ production respectively. DBD, DNA binding domain; TIR, Toll-interleukin-1 receptor domain; Asterisks indicate the location of each PRR within the cell: ${ }^{*}$, endosomal; ${ }^{* *}$, cell surface; ${ }^{* *}$, cytoplasmic. 